\title{
Evaluation of touch smears cytology and biopsy findings in the diagnosis of gastric carcinoma
}

\author{
Dhakhwa $\mathrm{R}^{1,2}$, Shrestha $\mathrm{HG}^{2}$, Joshi $\mathrm{DM}^{2}$, Lakhey $\mathrm{M}^{1}$

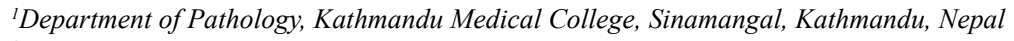 \\ ${ }^{2}$ Department of Pathology, Kathmandu Hospital Pvt. Limited, Tripureswar, Kathmandu, Nepal
}

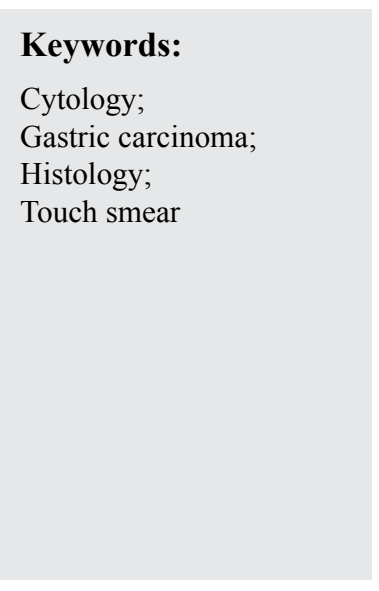

\begin{abstract}
Background: Gastric carcinoma is one of the leading causes of cancer deaths worldwide, with a mortality rate directly related to the stage at diagnosis. Endoscopic biopsy and cytology are well established techniques for the diagnosis of carcinoma of stomach.

Materials and Methods: This study was conducted on 50 patients, suspected of gastric cancer on endoscopy, during a period of 18 months (October 2010 to March 2012). Endoscopic biopsy and touch smear cytology were evaluated. Biopsy was considered gold standard for final diagnosis.

Results: A total of 50 cases were included out of which 36 were malignant and 14 cases were benign. Cytology was able to diagnose 33 out of 36 malignant cases. Of 17 cases which were diagnosed as benign on cytology, 3 cases turned out to be malignant on biopsy. The sensitivity and specificity of touch smear cytology are $91.6 \%$ and $100 \%$ respectively.
\end{abstract}

Conclusion: Touch smear cytology is a useful adjunct in the diagnosis of gastric carcinoma and should be considered a routine method along with biopsy.

\section{INTRODUCTION}

Gastric cancer is one of the most common malignancies of the gastrointestinal tract. In the evaluation of these lesions, the diagnostic value of cytology in addition to biopsy remains controversial. There is wide variability in the reported diagnostic accuracy rates for biopsy and cytology in gastric lesions. ${ }^{1}$ Determined efforts in Japan, where the disease is common, have led to remarkable improvements in diagnostic methods. ${ }^{2}$ Today, various cytologic techniques like brush cytology, crush preparation, touch smear cytology etc. are commonly used along with routine endoscopic biopsy. ${ }^{3}$ There are a few studies in the literature on the

\section{Correspondence:}

Dr. Ramesh Dhakhwa, MD

Department of Pathology, Kathmandu Medical College,

Sinamangal, Kathmandu, Nepal

Email:rdhakhwa@gmail.com role of touch smear cytology in gastric cancer., ${ }^{4,5}$ On the basis of available data, there is no general consensus as to whether cytology should be done routinely, only in selected instances or not at all. However, the use of touch smear as simple, cheap and rapidly available cytologic technique in under-resourced countries is an added asset to the biopsy. ${ }^{1,3}$

The aim of the present study was to evaluate the utility and accuracy of touch smear cytology in clinically suspected cases of gastric malignancy with a subsequent correlation with histopathology.

\section{MATERIALS AND METHODS}

From October 2010 to March 2012, 50 consecutive patients suspected of gastric malignancy were included in this study. On endoscopy, these patients had variable gastric lesions 
like mucosal thickening, ulcers, polypoid and ulcerative growths. The site and morphologic appearance of the lesions were recorded. Multiple biopsy samples were taken ranging from 2 to 6 tissue bits. The biopsy samples were transferred from the forceps to two slides with a fine needle, and the smears were then made by gently rotating the tissue with the needle. The touch smears were fixed immediately in $95 \%$ propanol for 30 minutes and then stained by Papanicolaou method. The biopsy was subsequently placed in formal saline for histopathologic processing. The histologic sections were routinely stained by hematoxylin and eosin method.

The smears and histologic sections were examined by two pathologists. In touch smears, the cytology slides were classified as positive, suspicious and negative for malignancy.

Positive cytology referred to those cases in which a diagnosis was established by the presence of frankly or unequivocally malignant cells. Suspicion of malignancy was kept in cases having atypical cells, suspicious but not confirmatory for malignancy. Cases that were unequivocally negative or had atypical cells consistent with an inflammatory or reparative process were considered negative. All suspicious cases were categorized as positive for statistical analysis. The data were collected and analyzed using SPSS version 11.0.

Histopathology report was considered gold standard for diagnosis of malignancy. Morphologic characterization and grading of carcinoma was done on histopathology sections.

\section{RESULTS}

Among 50 clinically suspicious cases of gastric malignancy, 27 proved to be malignant. It showed malignant cells arranged in papillaroid pattern. The cells show high NC ratio, moderate amount of cytoplasm and hyperchromatic nucleus with prominent nucleoli (fig.1\&2). Six cases were considered suspicious of malignancy on cytology. Both categories of cases with 'definitely malignant' and 'suspicious of malignancy'cytology were grouped under the category of 'positive for malignancy' for statistical evaluation. Sixteen cases were reported as negative for malignancy. In one of the cases, there was excessive drying and crushing artifacts and was considered unsatisfactory for evaluation. However, this case was kept under the category of negative for malignancy for valid statistical analysis.

Histological evaluation showed nonspecific chronic gastritis in 9 cases, benign gastric ulcer in 7 cases and malignancy in 34 cases. In two of the cases which showed benign gastric ulcers, cytology revealed cells with unequivocal malignancy. Repeat biopsy was performed in these two cases. The repeat biopsy however showed malignancy in

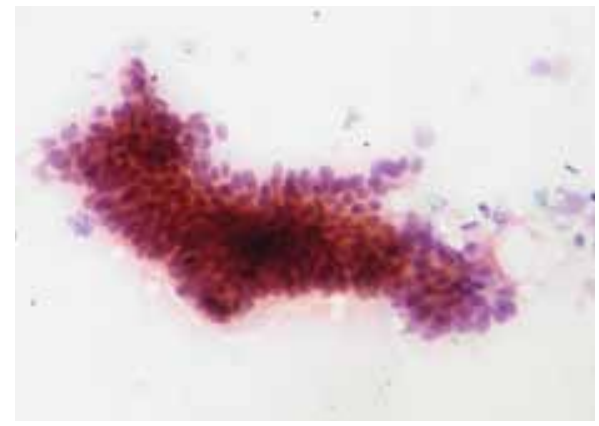

Figure 1: Touch smear cytology showing papillaroid fragment of malignant cells (Papanicolaou stain, X100)

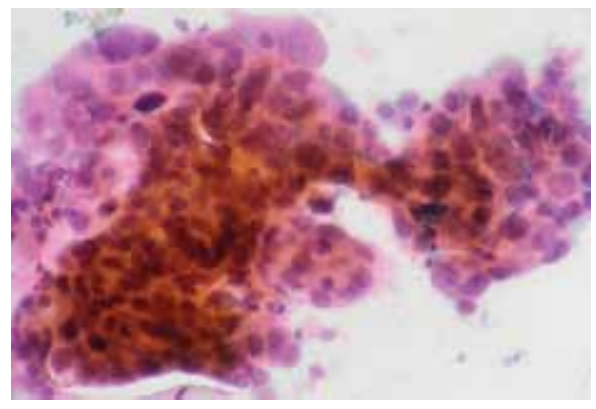

Figure 2: Touch smear cytology showing cohesive clusters of malignant cells (Papanicolaou stain, X400)

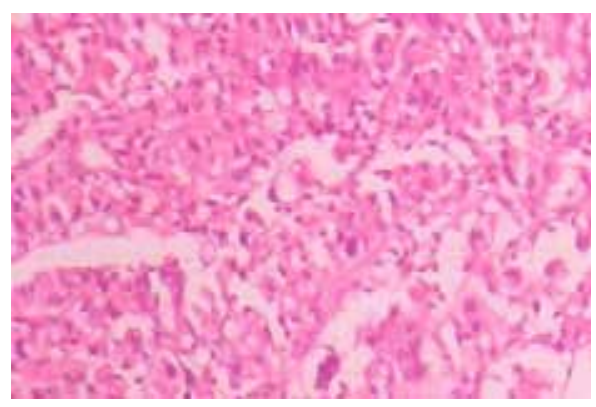

Figure 3: Poorly differentiated adenocarcinoma. Note the presence of signet ring cells. (HE stain, X200)

Table 1: Comparison of cytology and histology

\begin{tabular}{lccc}
\hline & $\begin{array}{c}\text { Malignant on } \\
\text { histology }\end{array}$ & $\begin{array}{c}\text { Benign on } \\
\text { histology }\end{array}$ & Total \\
\hline $\begin{array}{l}\text { Malignant on } \\
\text { cytology }\end{array}$ & 33 & 0 & 33 \\
$\begin{array}{l}\text { Benign on } \\
\text { cytology }\end{array}$ & 3 & 14 & 17 \\
\hline Total & $\mathbf{3 6}$ & $\mathbf{1 4}$ & $\mathbf{5 0}$ \\
\hline
\end{tabular}

Table 2: Sites involved in gastric adenocancer

\begin{tabular}{lc}
\hline Site of tumor & No. of cases \\
\hline Gastroesophageal junction & 9 \\
Cardia & 5 \\
Body & 7 \\
\hline Antrum & 15 \\
\hline
\end{tabular}


both of the cases, hence a final diagnosis of malignancy was made. Similarly, out of 16 cases which were diagnosed as negative on cytology, 2 turned out to be malignant on histology (fig. 3). One case which was unsatisfactory for evaluation on cytology, histology showed positive for malignancy. Table 1 compares the results of cytology with histology.

According to the above data, the sensitivity and specificity of cytology are $91.6 \%$ and $100 \%$ respectively. The positive predictive value of cytology is $100 \%$ where as the negative predictive value is $82.3 \%$.

The mean age of 36 patients finally diagnosed as gastric malignancy was 40 years with maximum patients in fourth decade. The male to female ratio was $2: 1$. Antrum of the stomach was the commonest site of involvement. Table 2 shows the commonest sites of gastric cancer. All 36 cases were adenocarcinoma, of which 7 were well differentiated, 10 moderately differentiated and 19 poorly differentiated. Resection specimens were available in 6 of the poorly differentiated carcinomas, of which 2 were sub-typed as signet ring cell carcinoma.

\section{DISCUSSION}

Endoscopy has greatly facilitated the detection of upper gastrointestinal (GI) lesions. ${ }^{6-8}$ Endoscopic biopsy has been the routine method of diagnosing gastric cancer, but there are controversies regarding the role of cytology. According to Francis et al, cytology is an invaluable adjunct in the diagnosis of gastric cancers where as other studies indicate that combining cytology with biopsy will increase false positive rates. ${ }^{9,10}$ Cook et al stressed the use of cytology only if there is any difficulty in obtaining adequate tissue. ${ }^{11}$

In our admittedly small series of cases, biopsy touch smear cytology could achieve diagnostic sensitivity and specificity of $91.6 \%$ and $100 \%$ respectively. Other studies have shown sensitivity ranging from 85 to $96 \% .^{5,12}$ Imprint cytology was found to be even more sensitive and superior to biopsy in some studies., ${ }^{2,13}$ In our study too, two cases which were originally negative on histology, cytology could diagnose malignancy, which was subsequently proven by a repeat biopsy. Hence, cytology offers a distinct advantage over histology in such type of cases as presence of few viable obviously malignant cells in touch smear are sufficient for diagnosis. On the contrary, single malignant cells or small clusters of cells may be overlooked or underestimated if a definite 'tissue pattern' is lacking in histologic sections. ${ }^{13}$ In cases with positive cytology and negative histology, it is however recommended that a reapeat biopsy should be done to confirm the diagnosis.
Although highly accurate in the diagnosis of malignancy, touch smear cytology can not replace biopsy examination for tumor typing and confirming the invasion of tumor. The two techniques of touch smear cytology and histology remain complementary and both should be utilized for maximum diagnostic accuracy. ${ }^{3,13}$

\section{CONCLUSION}

Touch smear cytology is a highly sensitive and specific technique for identification of gastric malignancy. It is a simple, rapid and cheap technique which may be routinely used along with endoscopic biopsy to ensure diagnostic accuracy.

\section{REFERENCES}

1. Geramizadeh B, Shafiee A, Saberfirruzi M, Kumar PK, Shaheem A. Brush cytology of gastric malignancies. Acta Cytol 2002;46:693-6.

2. Young JA, Hughes HE. Three year trial of endoscopic cytology of the stomach and duodenum. Gut 1980;21:241-6.

3. Batra M, Handa U, Mohan H, Sachdev A. Comparison of cytohistologic techniques in diagnosis of gastroesophageal malignancy. Acta Cytol 2008;52:77-82.

4. Kochhar R, Bhasin DK, Rajwanshi A, Gupta SK, Malik AK, Mehta SK. Crush preparations in gastro-esophageal biopsy specimens in diagnosis of malignancy. Acta Cytol 1990;34:214-6.

5. Gupta SC, Bisht D, Nigam DK, Singh PA. Fibreoptic endoscopy, endoscopic brush, biopsy imprint cytology and biopsy histology in lesions of upper gastrointestinal tract. Indian J Pathol Microbiol 1984;27:229-40.

6. Geisinger KR. Endoscopic biopsies and cytologic brushings of the esophagus are diagnostically complimentary. Am J Clin Pathol 1995;103:295-9.

7. Zargar SA, Khuroo MS, Jan GM, Mahajan R, Shah P: Prospective comparison of the value of brushings before and after biopsy in the endoscopic diagnosis of gastro-esophageal mialignancy. Acta Cytol 1991;35:549-52.

8. O'Donoghue JM, Horgan PG, O'Donohue MK et al. Adjunctive endoscopic brush cytology in detection of upper gastrointestinal malignancy. Acta Cytol 1995;39:28-34.

9. Francis C, Koprowska I, Berger A, Maier WP, Ming SC: The role of cytology in the diagnosis of carcinoma of stomach. Surg Gynecol 1983;151:601-3.

10. Wang H, Jonasson JG, Ducatman BS: Brushing cytology of upper gastrointestinal tract: Obsolete of not? Acta Cytol 1991;35:195-9.

11. Cook IJ, de Carle DJ, Haneman B, Hunt DR, Talley NA, Miller D: The role of brushing cytology in the diagnosis of gastric malignancies. Acta Cytol 1988;32:461-4.

12. Sharma P, Misra V, Singh PV, Misra SP, Gupta SC: A correlative study of histology and imprint cytology in the diagnosis of gastrointestinal tract malignancies. Indian J Pathol Microbiol 1997;40:139-46.

13. Young JA, Hughes HA, Lee FD. Evaluation of endoscopic brush and biopsy touch smear cytology and biopsy histology in the diagnosis of carcinoma of the lower oesophagus and cardia. J Clin Pathol 1980;33:811-4. 